\section{Cray and IBM in the frame}

\section{Sydney}

Australia's supercomputing capability is about to take a leap forward. An agreement between the Commonwealth Scientific and Industrial Research Organisation (CSIRO) and a commercial supercomputing bureau, Leading Edge Technologies, should bring a Cray Y-MP to the country by February next year. The A $\$ 10$ million machine, which will replace an out-ofdate Cyber 205 in Canberra, will be leased by CSIRO from Leading Edge and will also be available, at a cost, to industry and universities. The leasing arrangement is a consequence of an earlier miscalculation by CSIRO, which bought the Cyber 205 in 1984 in the expectation of a demand by industry. But industrial use of the machine fell far short of paying the cost.

Leading Edge, based in Melbourne, already has a Cray X-MP to which industry and academic researchers have access at $\mathrm{A} \$ 3,000$ an hour. According to Tom Kopp, managing director of Leading Edge, the hourly charge for the Y-MP is likely to be $A \$ 4,5000$.

Installation of the new machine will move the focus of Australian supercomputing from Canberra to Melbourne where, according to Bob Frater, director of the Institute for Information and Communication Technology for the CSIRO, most of the major supercomputer users reside. "Groups like the Division for Atmospheric Research and the Division of Biotechnology have, until now, been disadvantaged by having our supercomputer facilities in Canberra," he said.

The move to Melbourne will also be advantageous to the Strategic Research Foundation (SRF), an initiative of the state of Victoria to commercialize research developments by bringing academic groups such as CSIRO and the universities together with industry.

The Victorian government has promised support for the SRF to the tune of A $\$ 3$ million in $1988-89$ and $A \$ 7.5$ million a year over the next four years, with additional funding "if working groups identify proposals which would have a major impact on the Victorian economy."

The Cray Y-MP reserved for CSIRO is now on the assembly line in the United States. According to Ian Elsum, the manager of the CSIRO Information and Communication Technology Institute, this has created some pressure to get the deal signed. "Cray clearly cannot reserve the machine for CSIRO indefinitely. We didn't allow enough time for something of this complexity to go through. It's a bit of a rush," he said.

Contributing to the pressure is believed to be a lack of money on CSIRO's part to buy into the deal. According to Kim Sweeney, SRF project manager, "CSIRO doesn't have enough money to meet the cost of the Cray. They have approached us to meet the cost." SRF will discuss at 14 November board meeting whether to help CSIRO, but may invest in an IBM system.

According to sources in the SRF working party on advanced computing, IBM has approached the Victorian government with a "very competitive deal". But representatives of academic computer services groups on the SRF board favour a Cray, and a deal that linked the SRF to the CSIRO/Leading Edge Cray purchase would appease the computer buffs.

Sweeney says that people in computer advisory groups are urging SRF to look at the Cray leasing arrangement by CSIRO as the nucleus of supercomputing centre like those supported by the US National Science Foundation. SRF is willing to accommodate these desires "in one way or another".

Tanla Ewing

\section{FRENCH RESEARCH}

\section{Fifty and counting for CNRS}

\section{Paris}

France's chief basic research organization, the Centre National de la Recherche Scientifique (CNRS), celebrated its fiftieth anniversary this October in the presence of President François Mitterrand - the first visit in its history from the head of state. Although it would be wrong to say CNRS is lying about its age - the organization was officially founded on 19 October 1939 - it was only in 1945, after the Second World War and the end of the Nazi occupation, that CNRS took shape. Since then, it has grown to be Europe's largest basic research employer, with 26,000 staff, 17,000 of whom are researchers and technicians, and 1,300 research laboratories.

The size and centralized administration of CNRS have attracted criticism, and successive governments have attempted reforms. In 1986, Jacques Chirac's neogaullist government tried to dismantle what it called an unwieldy and unmanageable "mastodon" in an effort to return research and prestige to the universities. But the moves ended in the resignation of the research minister and riots in which a student died.

Although CNRS is relatively safe in the hands of the present socialist government, research minister Hubert Curien is shortly to announce measures that will change the way the organization is run. A former director-general of CNRS, Curien intends to limit the director-general's hand in the choice of heads of the $\mathbf{4 5}$ disciplines and to demand a drastic cut in the number of administrative disciplines.

\section{Six per cent of solution}

\section{London}

THE UK Department of Energy is considering proposals to build a barrage in the Severn estuary, at the southern junction of England and Wales, which could supply up to 6 per cent of Britain's future electricity needs. In a report published last month, the Severn Tidal Power Group and a consortium of civil engineers conclude that the scheme is feasible, and that "the level of confidence in the project, its buildability, programming and cost estimation have been considerable enhanced".

The plan is to erect a 10 -mile barrage across the Severn river between Brean Down, west of Weston-Super-Mare, to Lavernock Point near Cardiff, where the tidal range reaches 35 feet, its peak value along the estuary. The report, which cost $£ 4.26$ million, estimates that construction of the barrage could begin in 1993 with the first electricity being produced by 1999 .

The estimated cost of the barrage is $£ 8,280$ million at 1988 prices. There would be 216 turbines built into the wall which, given the Severn's unusually large intertidal range, could produce up to 7,200 megawatts - between 6 and 7 per cent of Britain's annual electricity requirement.

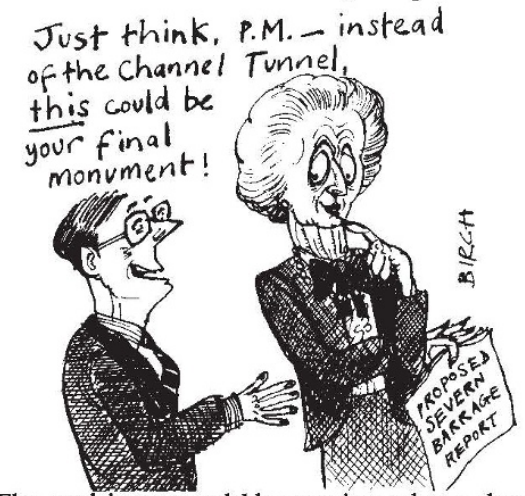

The turbines would be stationed at a depth of 100 feet in large hydraulic structures or caissons. The barrage, largest of a number of sites being considered by the Department of Energy, could be a source of clean energy for 100 years.

The report warns, however, that there would be environmental effects that need further study. But if the barrage replaced an equivalent coal- or oil-based electricitygenerating capacity, there would be a 17.6 million tonne reduction in carbon-dioxide emission, according to the report. The Department of the Environment is also assessing the barrage's potential for recreational activities and tourism.

The report concludes that the "the Severn Barrage remains the largest single renewable energy project which could make a significant contribution to the electrical energy supply on a reasonable timescale".

Ben Webb 